\title{
GREEN PLASTICS BASED ON THERMOPLASTIC STARCH AND STEAM-EXPLODED NANOFIBER CELLULOSE
}

\author{
E. Zaidar ${ }^{1}$, S. Lenny ${ }^{1}$, S.A. Amaturrahim ${ }^{1,3}$, S.A. Situmorang1,3 , J.N. Sari ${ }^{1,3}$, \\ S.U. Rahayu ${ }^{2,3}$ and S. Gea ${ }^{1,3, \bigotimes}$ \\ ${ }^{1}$ Department of Chemistry, Faculty of Mathematics and Natural Sciences, Universitas Sumatera \\ Utara, Medan-20155, Indonesia \\ ${ }^{2}$ Department of Physics, Faculty of Mathematics and Natural Sciences, Universitas Sumatera \\ Utara, Medan-20155, Indonesia \\ ${ }^{3}$ Cellulosic Functional Material-Research Center, Universitas Sumatera Utara, \\ Medan-20155, Indonesia \\ ${ }^{\otimes}$ Corresponding Author: s.gea@usu.ac.id
}

\begin{abstract}
Thermoplastic starch (TPS) is a potential candidate for green plastic or biodegradable plastic because it is renewable, cheap, translucent, and flexible. However, the mechanical properties of TPS are still not satisfactory and should be enhanced by adding reinforcing agents such as Nanofiber cellulose (NFC). This research aimed to fabricate the bioplastics based on thermoplastic starch (TPS) and Nanofiber cellulose (NFC) by solvent casting technique. NFC was prepared via physicochemical pretreatment of empty fruit bunches (EFB) through a steam explosion method. FTIR and XRD technique is used to evaluate the interaction between TPS and NFC. The addition of NFC increased the mechanical properties of the bioplastics from 27.9 to $42.7 \mathrm{MPa}$. TGA data showed that the degradation of bioplastics increased from $307^{\circ} \mathrm{C}$ to $313^{\circ} \mathrm{C}$ with a percentage of the residue of $1.8 \%$ and $10 \%$, respectively. SEM analysis showed that NFC was homogeneously dispersed on the TPS. Based on these results, it can be concluded that the addition of NFC improved mechanical and thermal properties that are potentially used as green plastic material.
\end{abstract}

Keywords: Bioplastics, Nanofiber Cellulose, Steam exploded, Thermoplastic Starch, Casting Method.

RASĀYAN J. Chem., Vol. 14, No.2, 2021

\section{INTRODUCTION}

Plastics have great mechanical properties and strong barrier capacity for water and air; it is also considered to be low-cost, light in weight, easy processing so that it is often used as plastic packaging; however, it needs 500-1,000 years to decompose., ${ }^{1,2}$ This issue creates many problems for the environment. Therefore, the search for new materials for plastics that are biodegradable, renewable, and inexpensive is needed. ${ }^{3}$ Some companies have used oxo-degradable and biodegradable plastic which is decomposed in 2 years and 10 weeks, respectively, to solve the plastic problem. ${ }^{4}$ Nowadays, researchers have developed biodegradable plastic or 'bioplastic' technology based on cellulosic esters ${ }^{5}$, starch derivatives (TPS $)^{6}$, polyhydroxy butyrate $(\mathrm{PHB})^{7}$, polylactic acids $(\mathrm{PLA})^{8}$, and polycaprolactone $(\mathrm{PCL}){ }^{9}$ Bioplastic development is hampered by higher production costs when compared to conventional plastics; however, a comprehensive analysis not only considers the costs of production but also considers the costs associated with managing the waste produced. ${ }^{10}$

Regarding that, starch is a promising raw material to produce bioplastics because of abundant in nature, easy to degrade, inexpensive, and has good physicochemical properties. Besides, the properties of starch are almost the same as a synthetic polymer (plastic) after it is thermodynamically treated with the addition of a plasticizer. ${ }^{11}$ The plasticizer is often added to enhance the thermomechanical properties of bioplastic by reducing the rigidness so that it becomes more elastic. ${ }^{12}$ Thermoplastic starch (TPS) is widely used in diverse applications, especially in the packaging industry. However, starch has several disadvantages such as brittle, unsatisfactory thermo-mechanical properties, high permeability to gases, and poor water- 
holding properties. ${ }^{13}$ One approach to overcome these disadvantages is by adding a reinforcement agent to the matrix of starch to obtain high-performance TPS-based composite materials. In the previous study, various biodegradable polymer for example poly(vinyl alcohol) $(\mathrm{PVA})^{14}$, polycaprolactone $(\mathrm{PCL})^{15}$, poly(ester amide) (PEA) ${ }^{16}$, and chitosan ${ }^{17}$ synthetic have been mixed with starch; furthermore, several natural fibers such as jute, flax, and corn fibers are also used. ${ }^{18}$

The previous investigation has exhibited that the addition of fibers containing up to $30 \%$ into TPS not only improves the mechanical properties and barrier ability but also reduces aging in the material. ${ }^{19}$ Dang and Yoksan ${ }^{20}$ which studied the blend TPS with chitosan-based blown film extrusion for food packaging, showed that by adding $0.37-1.45 \%$ of chitosan, the tensile strength and Young's Modulus of the film have enhanced (8-97\% and $40-154 \%$, respectively) as well as reduced capability of water absorption and improved thermal stability, but the opacity has increased. Regarding that, Nanofiber cellulose (NFC) is a natural fiber with characteristics such as biodegradable, biocompatibility, high crystallinity, great mechanical properties, low coefficient of thermal expansion, and high porosity. ${ }^{21,22}$ Chang et al. ${ }^{23}$ showed that the addition of $0-5 \mathrm{wt} \%$ cellulose nanoparticle $(\mathrm{CN})$ content in wheat starch casting composite improved the tensile strength from 3.15 to $10.98 \mathrm{MPa}$ and increased the thermal stability of the composite. NFC is expected to improve the mechanical properties of TPS since it has a similar chemical structure to TPS; thus, providing a good interaction between the two. Also, it is predicted that the thermal properties become better and enhance the water resistance and the stability toward different relative humidity, resulting in good bioplastics, especially as a promising food packaging.

Investigated the impact of the addition of NFC to improve the mechanical and thermal properties of TPS in fabricating bioplastic is the main purpose of this research. The NFC was extracted by using a steam explosion with the addition of chemical treatment. This process is very important to remove any unwanted component such as lignin and hemicellulose so pure NFC was obtained. ${ }^{24}$ Further, the solvent casting technique is employed due to its effectiveness in manufacturing bioplastics on a laboratory scale based on hydrosoluble polymer ${ }^{11,21}$ and kept NFC disperse in matrix TPS so the homogenous thickness distribution of film bioplastic can be obtained.

\section{EXPERIMENTAL}

\section{Isolation of Nanofiber Cellulose by Steam Explosion}

EFB (Empty Fruit Bunches) fiber from oil palm plantation developed by Universitas Sumatera Utara was prepared and ground into small pieces. EFB fiber was soaked in $\mathrm{NaOH} 2 \%$ for 24 hours and then autoclave at a pressure of $168.9 \mathrm{kPa}$ at $130^{\circ} \mathrm{C}$ for 4 hours after treated in $\mathrm{NaOH} 12 \%$ with ratio fiber to alkaline solution 1:10. The fiber was rinsed in distilled water until neutral. Furthermore, the fiber was washed with $17.5 \% \mathrm{NaOH}: 7.4 \% \mathrm{CH}_{3} \mathrm{COOH}$ : $1.75 \% \mathrm{NaOCl}$ solution with a ratio of 1:1:6. ${ }^{25} \mathrm{~A} 10 \% \mathrm{H}_{2} \mathrm{O}_{2}$ was used to bleach the fiber. Then, the bleached fiber was neutralized using distilled water and dried. NFC was obtained by acid hydrolysis using $10 \% \mathrm{HCl}$ and ultrasonic for 3 hours at room temperature. Finally, after the NFC was neutralized again, It stirred with a homogenizer for 30 minutes at 8,000 rpm at room temperature to avoid fiber agglomeration.

\section{Preparation of Nanofiber Cellulose/Thermoplastic Starch Bioplastic}

TPS/NFC bioplastic was prepared by solvent casting technique. The NFC with variation $10 \%$ and $20 \%$ (based on the dry weight of TPS) was added into the solution of TPS (cassava starch $7 \mathrm{wt} \%$ and glycerol $3 \mathrm{wt} \%$ in distilled water) and were mixed by using a homogenizer for 30 minutes at $8000 \mathrm{rpm}$. Then the mixture was continuously stirred at $300 \mathrm{rpm}$ and heated at $100^{\circ} \mathrm{C}$ until it became viscous and transparent. After the mixture cooled down to $70^{\circ} \mathrm{C}$, it cast on the Petri dish. Finally, the bioplastic was evaporated in the oven at $50^{\circ} \mathrm{C}$ for 2 days.

\section{Characterization}

The morphology TPS/NFC bioplastic is observed by EVO MA 10 carl Zeiss Bruker scanning electron microscope (SEM) operating at $20 \mathrm{kV}$ to investigate the homogeneity of the surface. The Fourier transform infrared spectroscopy (FTIR) was performed on Shimadzu IR Prestige-21 spectrometer at 500$4000 \mathrm{~cm}^{-1}$ of wavenumber to observe interactions between the components of bioplastic. The X-ray 
RASĀYAN J. Chem.

Vol. 14 | No. 2 |1281-1288| April - June | 2021

diffractograms were recorded by Shimadzu XRD-6100 with $\mathrm{Cu}-\mathrm{K} \alpha$ radiation to evaluate the crystallography. The mechanical properties were measured according to ASTM D 638-98 specimen IV using a GOTECH Al $7000 \mathrm{M}$ tensile strength tester under ambient temperature and humidity $\left(20^{\circ} \mathrm{C}, 65 \%\right.$ $\mathrm{RH}$ ) with a $1 \mathrm{kN}$ static load cell. Meanwhile, thermogravimetric analysis (TGA) is obtained by using TGA SDT Q600 V20 at the temperature of $35-600^{\circ} \mathrm{C}$ with a flow rate of $10^{\circ} \mathrm{C} / \mathrm{min}$.

\section{RESULTS AND DISCUSSION}

The micrographs of cassava starch, TPS, NFC, bioplastics of TPS/NFC $10 \%$ and TPS/NFC $20 \%$ are observed in Fig.-1 (a), (b), (c), (d), (e), (f) and (g) respectively. Figure-1(a) shows the presence of elliptical, oval, and spherical granules in different sizes. The granules display a smooth surface without any deformity or flaws. Cassava starch granular has a gelatinization process with the presence of water and glycerol to form a starch paste. Figure-(b) shows that there is no granule of starch appears in the TPS film, but the surface still looks irregular. Water and glycerol as plasticizers destroy starch granules physically by stirring at high temperatures, moreover, they also interfere with the inter- or intramolecular hydrogen bonds of starch, forming TPS. ${ }^{26}$ In Fig.-1(c) the morphology of NFC exhibit that fiber form an entangled network with fiber separates individually in a bundle because of hemicellulose, lignin, and pectin removed after physicochemical pretreatment. In Fig.-1(d) the TPS/NFC bioplastic $10 \%$ at 1,000x magnification shows the surface slightly uneven due to random distribution of NFC on the TPS matrix, further 5,000x magnification in Fig.-1(f) clearly shows that NFC fiber agglomerated on one side in TPS matrix. However TPS/NFC $20 \%$ with the same magnification has a more homogeneous surface, and NFC is well dispersed throughout the TPS matrix as shown in Fig.-1(e) and Fig.-1(g).
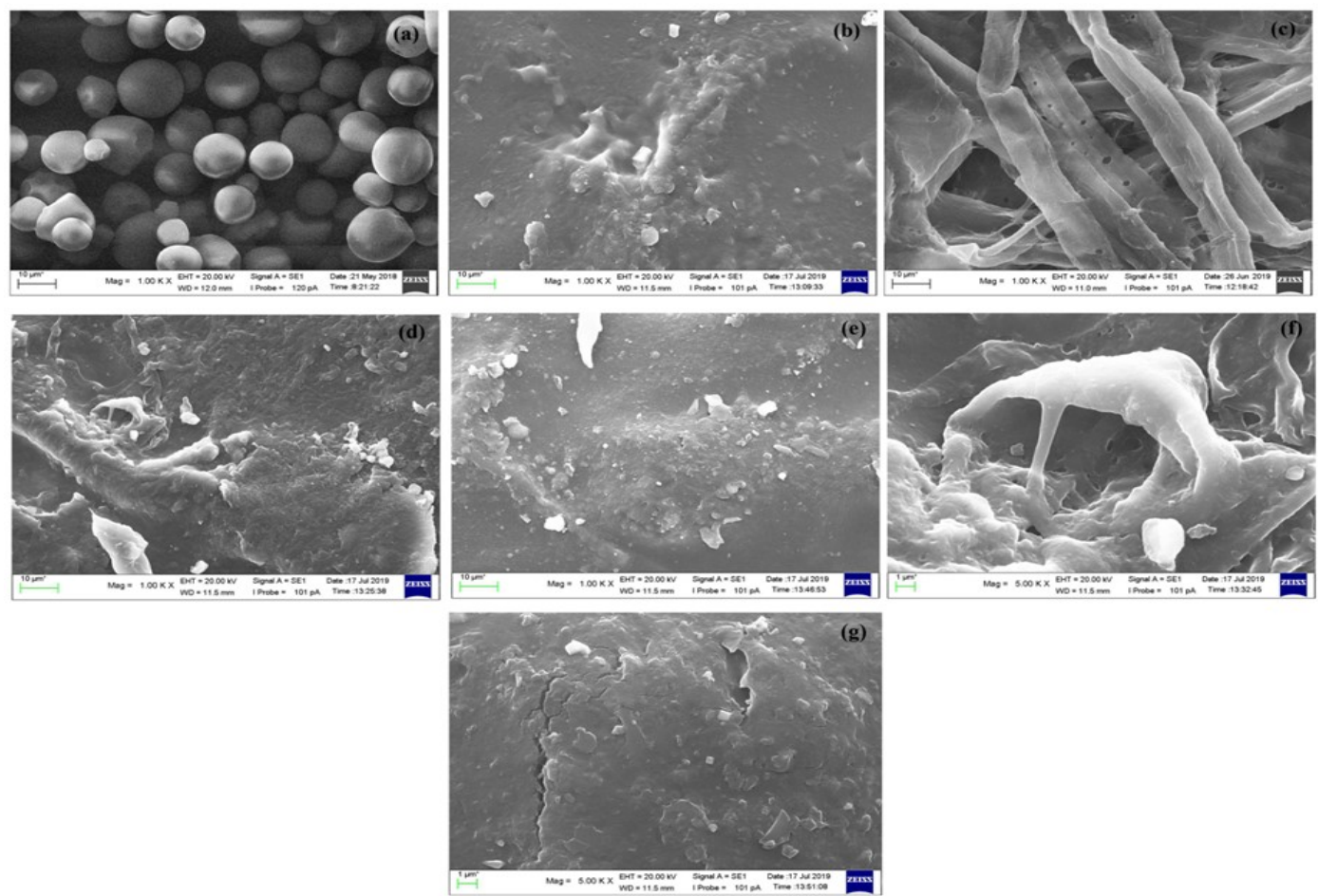

Fig.-1: The SEM Result of (a) Granule Native of Cassava Starch, (b) Thermoplastic Starch (TPS) Film, (c)

Nanofiber Cellulose (NFC), (d,) Bioplastic of TPS/NFC 1g with magnification 1000 times, (e) Bioplastic of TPS/NFC 20\% with magnification 1000 times, (f) Bioplastic of TPS/NFC 10\% with magnification 5000 times, (g) Bioplastic of TPS/NFC $20 \%$ with magnification 5000 times.

The FTIR spectra of TPS, NFC, and bioplastic of TPS/NFC are illustrated in Fig.-2. TPS has two main absorption bands which represent the component, namely starch and glycerol. Starch molecule is characterized at $3379 \mathrm{~cm}^{-1}$ (OH stretching), $2931 \mathrm{~cm}^{-1}$ (CH stretching), $1635 \mathrm{~cm}^{-1}$ (absorbed water), 1373 
RASĀYAN J. Chem.

Vol. 14 | No. 2 |1281-1288| April - June | 2021

$\mathrm{cm}^{-1}\left(\mathrm{CH}_{2}\right), 925 \mathrm{~cm}^{-1}$ (pyranose ring), $1033 \mathrm{~cm}^{-1}$ (COH bending), $1149 \mathrm{~cm}^{-1}$ (CO stretching). The presence of glycerol as a plasticizer can be observed at $1411 \mathrm{~cm}^{-1} \cdot 27,28$ NFC exhibites characteristic band at 3387 $\mathrm{cm}^{-1}$ (OH stretching), $2916 \mathrm{~cm}^{-1}$ (CH stretching), $1635 \mathrm{~cm}^{-1}$ (absorbed water), $1427 \mathrm{~cm}^{-1}(\mathrm{C}=\mathrm{C}$ aromatic ring of lignin), $1319 \mathrm{~cm}^{-1}$ (asymmetrical $\mathrm{CH}$ bending), $1056 \mathrm{~cm}^{-1}$ (COH bending), $1111 \mathrm{~cm}^{-1}$ (CO stretching) and $894 \mathrm{~cm}^{-1}$ ( $\beta$-glycoside bonds). ${ }^{29}$

There is a slight difference in the intensity of TPS before and after the addition of NFC. From the spectra, there was a hydrogen-bonding interaction between TPS and NFC. It was confirmed by the $\mathrm{OH}$ absorption band of TPS shifted to a higher wavenumber from $3379 \mathrm{~cm}^{-1}$ to $3394 \mathrm{~cm}^{-1}$ with the addition of NFC. ${ }^{20}$ The result implied that the hydrogen bonds between starch become weaker replaced by hydrogen bonds formed between hydroxyl groups of TPS and NFC. ${ }^{20}$

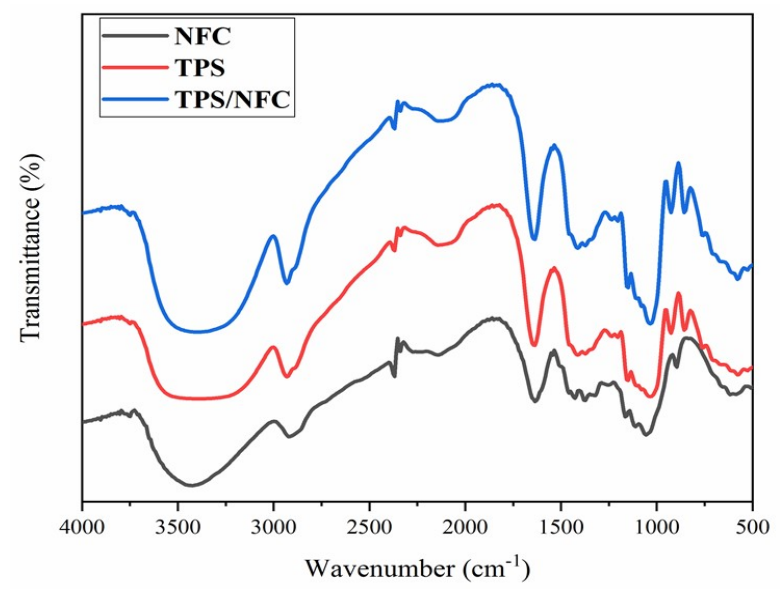

Fig.-2: FTIR Spectra of TPS Film, NFC, and Bioplastic of TPS/NFC

The XRD pattern of starch granular, NFC, TPS film, bioplastic of TPS/NFC is seen in Fig.-3. Regarding Fig.-3, Cassava starch granular showed diffraction at angles of $(2 \theta) 15.1^{\circ}, 19.8^{\circ}, 23.3^{\circ}$, and a doublet at $17.1^{\circ}$ and $18.0^{\circ}$, which have been reported. ${ }^{30}$ During the process, starch granules are destructed by heat and mechanical force, hence, amylose which is a linear polymer dissociates out of the granules and crystallizes mostly into a single helix crystal structure..$^{29}$ The amorphous regions of starch increased. The TPS film has diffraction at $13.9^{\circ}, 16.7^{\circ}, 18.2^{\circ}, 19.3^{\circ}$ and $22^{\circ}$ with the explanation following. The peaks at $13.9^{\circ}$ and $19.3^{\circ}$ represent type- $\mathrm{V}_{\mathrm{H}}$ formed by amylose and glycerol. ${ }^{20}$ It is broaden owing to the large amorphous content. Also, the crystalline structure of the natural starch granules disappears during the bioplastic manufacturing process. The peaks at $18.2^{\circ}$ and $22^{\circ}$ represent type $\mathrm{B}$ that may be formed during storage. High water content in materials during storage time at humidity $(>60 \%)$ can accelerate the formation of B-type crystals because of the high mobility of the starch molecular chain. The peak at $16.7^{\circ}$ indicates the characteristic of amylopectin that undergoes recrystallization from type-B formed during the process. $^{31}$

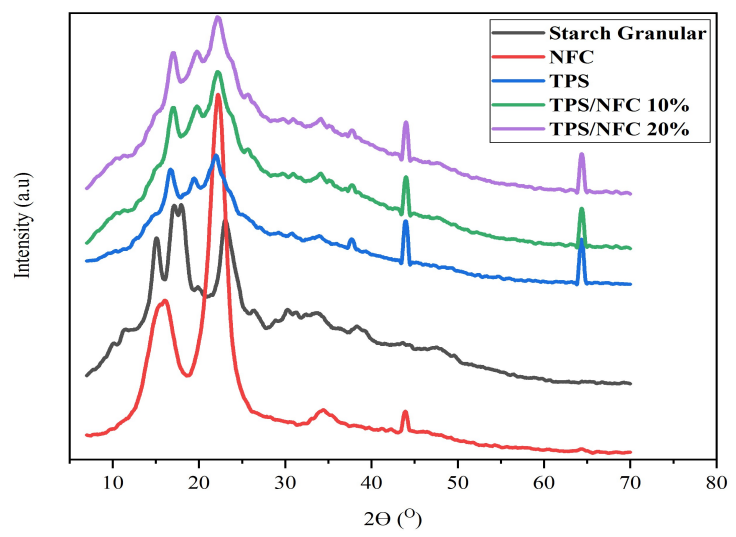

Fig.-3: XRD Pattern of Starch Granule, TPS Film, NFC, Bioplastic of TPS/NFC 10\%, Bioplastic of TPS/NFC $20 \%$. 
RASĀYAN J. Chem.

Vol. 14 | No. 2 |1281-1288| April - June | 2021

The X-Ray diffractogram of NFC shows sharp diffraction peaks at $20.6^{\circ}$ and $22.1^{\circ}$ which characteristically represents cellulose type II. ${ }^{32}$ The intensity at $22^{\circ}$ increases and sharpens with the addition of NFC into TPS. This is due to the presence of NFC $22.4^{\circ}$ indicating the crystal lattice plane 002 in cellulose. NFC has a high degree of crystallinity because acid hydrolysis eliminates the amorphous region and results in a more stable crystalline region. ${ }^{29}$ Type- $\mathrm{V}_{\mathrm{H}}$ peaks widen with the increasing content of NFC, implying that the number of complexes formed between amylose and glycerol decreases due to restrictions on the movement of amylose chains when hydrogen bonding interactions formed between starch and NFC. ${ }^{20}$

The reinforcing effect of NFC as filler in the TPS matrix can be investigated based on the mechanical properties of bioplastic observed on the stress-strain curve in Fig.-4. Tensile strength, elongation at break, and Young Modulus from TPS films and TPS/NFC bioplastic are summarized in Table-1.

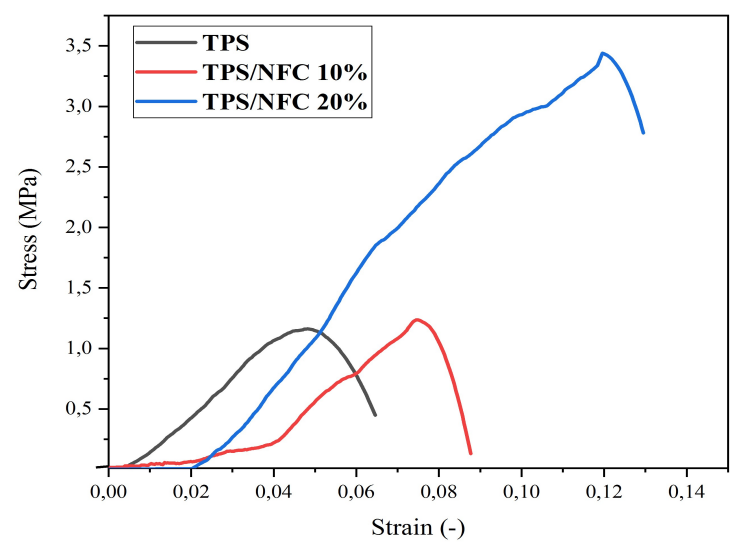

Fig.-4: Stress-strain Curves of TPS Film, Bioplastic of TPS/NFC 10\%, Bioplastic of TPS/NFC 20\%.

Table-1: The Mechanical Properties of TPS Film, TPS/NFC 10\%, and TPS/NFC 20\%

\begin{tabular}{c|c|c|c|c}
\hline No. & Sample & Young's Modulus (MPa) & Tensile Strength (MPa) & Elongation at Break (\%) \\
\hline 1. & TPS & 27.9 & 1.16 & 4.8 \\
\hline 2. & TPS/NFC $10 \%$ & 28.62 & 1.23 & 7.4 \\
\hline 3. & TPS/NFC $20 \%$ & 42.76 & 3.4 & 11.9 \\
\hline
\end{tabular}

NFC as the filler has been improved the mechanical properties of the bioplastics. The Young's Modulus increased significantly from 27.9 to $42.8 \mathrm{MPa}(65 \%)$ with the addition of $20 \%$ of NFC. This is owing to the strong physical interaction between NFC and TPS in the form of hydrogen bonds and a good transfer of stress from the matrix to the fiber so that limiting the mobility of starch molecules. Strong interaction between TPS and NFC can occur because NFC has a large specific surface area ${ }^{33}$ and have chemical structure similarities. Furthermore, NFC has a strong intermolecular hydrogen bond between its hydroxyl groups. Hence, it increased the mechanical properties of bioplastic. ${ }^{13}$ However, at lower content of NFC $(10 \%)$, there was no significant improvement in the mechanical properties of TPS/NFC bioplastic. It was probably caused by agglomeration and low dispersion NFC in the TPS matrix so that decreasing interfacial adhesion. ${ }^{34}$

TGA analysis was performed to evaluate the impact of the addition of NFC as fillers on the TPS matrix to the thermal properties of the bioplastics based on the determination of \% weight loss by increasing temperature continuously. Thermogravimetric curves of TPS and TPS/NFC bioplastics can be observed in Fig.-5 and summarized in Table-2.

From the curve, all samples are almost the same and consist of three main stages. The first stage shows the process of dehydration of water which starts immediately when the temperature rises and goes down around $110^{\circ} \mathrm{C}$ and then it is followed by evaporation of glycerol at a temperature above $200^{\circ} \mathrm{C}$. The percentage of weight loss at this stage depends on the moisture content in the sample. ${ }^{35}$ The second stage 
RASĀYAN J. Chem.

Vol. 14 | No. 2 |1281-1288| April - June | 2021

is the process of degradation and decomposition of the sample which starts at $300^{\circ} \mathrm{C}-350{ }^{\circ} \mathrm{C}$. In this process, the dehydration of the hydroxyl group from the glucose ring forms levoglucosan and is followed by the formation of the aldehyde group when the glucose ring was destructed. Aromatic rings, such as benzene substituted and furan with $-\mathrm{CH}_{2}-$ or- $\mathrm{CH}_{2}-\mathrm{O}_{-} \mathrm{CH}_{2}$ as the main chain in aromatic groups are produced with increasing temperature ${ }^{36}$. The last stage is the process of carbonization of the sample which starts at a temperature above $500^{\circ}$ that was confirmed by an increasing intensity relative to aromatic carbon resonance with decreasing aliphatic carbon intensity. ${ }^{36}$

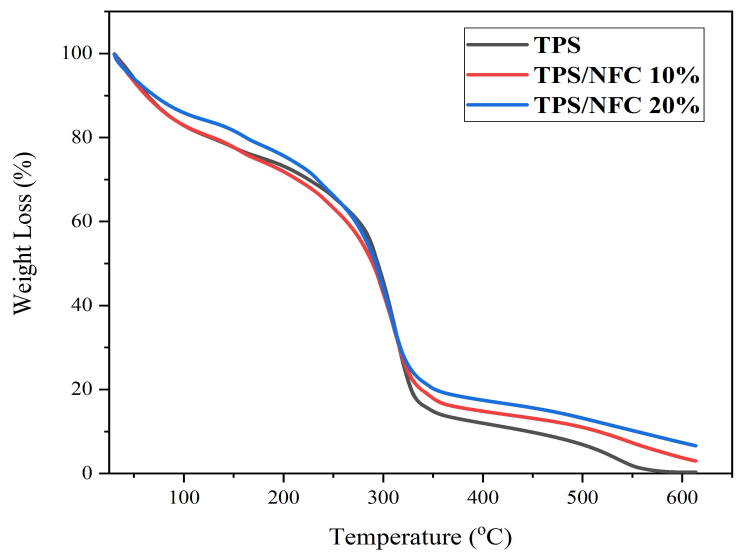

Fig.-5: TGA Curve of TPS Film, Bioplastic of TPS/NFC 10\%, Bioplastic of TPS/NFC 20\%

Table-2: \% Weight Loss and Temperature Maximum ( $\mathrm{T}_{\mathrm{Max}}$ ) of the Sample at Various Temperature

\begin{tabular}{c|c|c|c|c}
\hline No. & Sample & \% Residue Mass at $550^{\circ} \mathrm{C}$ & $\mathrm{T} \mathrm{Max}\left({ }^{\circ} \mathrm{C}\right)$ & Rate of Degradation $(\mathrm{mg} / \mathrm{min})$ \\
\hline 1. & TPS & 1.8 & 307 & 0.54 \\
\hline 2. & TPS/NFC $10 \%$ & 7.3 & 312 & 0.58 \\
\hline 3. & TPS/NFC $20 \%$ & 10.3 & 313 & 0.61 \\
\hline
\end{tabular}

Table-2 shows that all samples have the same maximum degradation temperature. The degradation temperature of both TPS and NFC starts at around $300^{\circ} \mathrm{C}$ and ends at approximately $350^{\circ} \mathrm{C}$. This occurs because the components of bioplastics coming from polymers with the same monomers, namely glucose. At the initial temperature of $300^{\circ} \mathrm{C}$, the TPS film has better thermal resistance compared to TPS/NFC bioplastics, but when temperature approaching $350^{\circ} \mathrm{C}$, the TPS/NFC bioplastic films show better thermal resistance as confirmed by the \% value of weight loss at the same temperature. The increasing NFC content can improve the thermal degradation resistance of bioplastics. TPS/NFC $20 \%$ bioplastics have $\mathrm{T}_{\max }$ degradation at $313^{\circ} \mathrm{C}$ with a final residual mass of $10.3 \%$ from the initial mass while TPS film $\mathrm{T}_{\max }$ degradation at $307^{\circ} \mathrm{C}$ with a final residual mass of $1.8 \%$. The interfacial surface area between TPS and NFC increased the ability of the amylopectin chain to crystallize the formed crystalline region that may be around the fibrils of NFC so that it improved the mechanical properties of bioplastics.

\section{CONCLUSION}

In this study, green plastics were prepared by mixed thermoplastic starch and steam-exploded Nanofiber celluloses from empty fruit bunches via solvent casting technique. TPS and NFC have chemical structure similarities so that provides good interaction of two forming hydrogen bond and it was analyzed using FTIR. The crystallography of bioplastic and their component was investigated by XRD. Good interaction between TPS and NFC increased the mechanical properties of the bioplastics that Young's modulus with the addition of $20 \%$ NFC rise from 27.9 to $42.7 \mathrm{MPa}$. Furthermore, the addition of $20 \% \mathrm{NFC}$ also increased the thermal properties of bioplastic because of the highly crystalline NFC. $\mathrm{T}_{\max }$ degradation rose from $307^{\circ} \mathrm{C}$ to $313{ }^{\circ} \mathrm{C}$ with percent residue $1.8 \%$ and $10 \%$ respectively. SEM analysis showed that NFC was homogeneously dispersed on the TPS. We conclude that the addition of NFC to TPS enhances the thermal and mechanical properties of bioplastic so that it can be applied as a bioplastic material, especially for food packaging. 
RASĀYAN J. Chem.

Vol. 14 | No. 2 |1281-1288| April - June | 2021

\section{ACKNOWLEDGEMENT}

The author would like to express gratitude to the Rector of Universitas Sumatera Utara for funding support through TALENTA 2018 via Applied Research Funding Scheme with contract number 2590/UN5.1.R/PPM/2018.

\section{REFERENCES}

1. R.Geyer, J.R. Jambeck, K.L. Law, Science Advances, 3(7), 25(2017), DOI:10.1126/sciadv.1700782

2. C. Amni, Ismet, S.Aprilia, Mariana, S.A. Akbar, Rasayan Journal of Chemistry, 13(1), 275(2020), DOI: $10.31788 /$ RJC.2020.1315492

3. A.K. Mohanty, M. Misra, L.T. Drzal, Journal of Polymers and the Environment, 10, 19(2002), DOI:10.1023/A:1021013921916

4. M. Cornelia, Ph.D. Thesis, Departement of Natural Resources and Environmental Management, Bogor Agricultural Institute, Bogor, West Java, Indonesia (2013)

5. H.M. Park, M. Misra, L.T. Drzal, A.K. Mohanty, Biomacromolecules, 5, 2281(2004), DOI: $10.1021 / \mathrm{bm} 049690 \mathrm{f}$

6. C. Bastioli, P. Magistrali, S.G. Garcia, 2012, Starch in Polymers Technology, in: K. Khemani, et al, Degradable Polymers and Materials: Principles and Practice (2nd Edition), ACS Symposium Series, American Chemical Society, Washington DC, pp. 87-112, DOI:10.1021/bk-2012-1114.ch007

7. K.G. Harding, J.S. Dennis, H. von Blottnitz, S.T.L. Harrison, Journal of Biotechnology, 130, 57(2007), DOI:10.1016/j.jbiotec.2007.02.012

8. Y. Tokiwa, B.P. Calabia, Applied Microbiology and Biotechnology, 72, 244(2006), DOI: 10.1007/s00253-006-0488-1

9. A. Demirbas, Energy Sources, Part A: Recovery, Utilization, Environmental Effects, 29(5), 419(2007), DOI:10.1080/009083190965820

10. F. Gironi, V. Piemonte, Energy Sources, Part A: Recovery, Utilization, Environmental Effects, 33(21), 1949(2011), DOI:10.1080/15567030903436830

11. Y. Zhang, C. Rempel, Q. Liu, Critical Reviews in Food Science Nutrition, 54(10), 1353(2014), DOI: 10.1080/10408398.2011.636156

12. M. Hasan, Zulfadli, M. Nazar, R.F.I Rahmayani, G. Fajri, H. Fansuri, Rasayan Journal of Chemistry, 12(3), 1390(2019), DOI:10.31788/RJC.2019.1235326

13. C.M.O. Muller, J.B. Laurindo, F. Yamashita, Food Hydrocolloids, 23(5), 1328(2009), DOI:10.1016/j.foodhyd.2008.09.002

14. P. Cinelli, V. Chiellini, J.W. Lawton, S.H. Imam, Polymer Degradation Stability, 91, 1147(2006), DOI: $10.1016 /$ j.polymdegradstab.2005.07.001

15. D. Preechawong, M. Peesan, P. Supaphol, V. Rujiravanit, Polymer Testing, 23, 651(2004), DOI: 10.1016/j.polymertesting.2004.01.011

16. E. Schwach, L. Avérous, Polymer International, 53(12), 2115(2004), DOI:10.1002/pi.1636

17. J. Nakamatsu, F.G. Torres, O.P. Troncoso, Y. Min-Lin, A.R. Boccaccini, Biomacromolecules, 7, 3345(2006), DOI:10.1021/bm0605311

18. N. Soykeabkaew, P. Supaphol, R. Rujiravanit, Carbohydrate Polymers, 58, 53(2004). DOI: $10.1016 / j$.carbpol.2004.06.037

19. A.M. Nafchi, M. Moradpour, M. Saeidi, A.K. Alias, Starch/Stärke, 65(1-2), 61(2013), DOI: $10.1002 /$ star.201200198

20. K.M. Dang, R. Yoksan, Carbohydrate Polymers, 115, 575(2015), DOI: 10.1016/j.carbpol.2014.09.005

21. E.D.M. Teixeira, C. Lotti, A.C. Corrêa, K.B.R. Teodoro, J.M. Marconcini, L.H.C. Mattoso, Journal Applied Polymer Science, 120, 2428(2011), DOI:10.1002/app.33447

22. H. Takagi, A. Asano, Composites Part A: Applied Science Manufacturing, 39, 685(2008), DOI: 10.1016/j.compositesa.2007.08.019

23. P.R. Chang, R. Jian, P. Zhen, J. Yu, X. Ma, Carbohydrate Polymers, 79(2), 301(2010), DOI: 10.1016/j.carbpol.2009.08.007

24. R. Lubis, B. Wirjosentono, Eddiyanto, A.A. Septevani, Rasayan Journal Chemistry, 13(3), 1287

GREEN PLASTICS

E. Zaidar et al. 
RASĀYAN J. Chem.

Vol. 14 | No. 2 |1281-1288| April - June | 2021

1767(2020), DOI:10.31788/RJC.2020.1335807

25. S. Gea, Z. Zulfahmi, D. Yunus, A. Andriayani, Y.A. Hutapea, In proceedings of The 2nd International Conference of Science (ICOS), Medan, Indonesia, 979 pp. 012063(2018), DOI: $10.1088 / 1742-6596 / 979 / 1 / 012063$

26. R. Bodîrlău, C.A. Teacă, I. Spiridon, N. Tudorachi, Monatshefte fuer Chemie, 143(2), 335(2012), DOI: $10.1007 / \mathrm{s} 00706-011-0659-3$

27. R. Kizil, J. Irudayaraj, K. Seetharaman, Journal Agricultural and Food Chemistry, 50(14), 3912(2002), DOI:10.1021/jf011652p

28. F. Delval, G. Crini, S. Bertini, Journal of Applied Polymer Science, 93, 2650(2004), DOI:10.1002/app.20851

29. A. Kaushik, M. Singh, G. Verma, Carbohydrate Polymers, 82(2), 337(2010), DOI: 10.1016/j.carbpol.2010.04.063

30. A. Kawabata, N. Takase, E. Miyoshi, S. Sawayama, T. Kimura, K. Kudo, Starch/Stärke, 46(12), 463(1994), DOI: 10.1002/star.19940461204

31. E.M. Teixeira, D. Pasquini, A.A.S. Curvelo, A. Corradini, M.N. Belgacem, A. Dufresne, Carbohydrate Polymers, 78, 422(2009), DOI:10.1016/j.carbpol.2009.04.034

32. B. Nasri-Nasrabadi, T. Behzad, R. Bagheri, Fibers and Polymers, 15(2), 347(2014), DOI: $10.1007 / \mathrm{s} 12221-014-0347-0$

33. M. Hietala, A.P. Mathew, K. Oksman, European Polymer Journal, 49(4), 950(2013), DOI: 10.1016/j.eurpolymj.2012.10.016

34. M.G. Lomelí-Ramírez, A.J. Barrios-Guzmán, S.G. Enriquez, J.J. Rivera-Prado, R. ManríquezGonzález, Bioresources, Thermo-starch \& Wood, 9(2), 2960(2014).

35. X. Liu, Y. Wang, L. Yu, Z. Tong, L. Chen, H. Liu, X. Li, Starch/Stärke, 65(1-2), 48(2013), DOI: $10.1002 /$ star.201200198

36. J. Liang, J. Chen, S. Wu, C. Liu, M. Lei, Sustainable Energy and Fuels, 2(8), 1855(2018), DOI: $10.1039 / \mathrm{c} 8 \mathrm{se} 00166 \mathrm{a}$

[RJC-5929/2020] 